This is an electronic reprint of the original article. This reprint may differ from the original in pagination and typographic detail.

Author(s): Kettunen, Jaana; Vuorinen, Raimo; Ruusuvirta, Outi

Title: $\quad$ European Lifelong Guidance Policy Network representatives' conceptions of the role of information and communication technologies related to national guidance policies

Year: $\quad 2016$

Version:

Please cite the original version:

Kettunen, J., Vuorinen, R., \& Ruusuvirta, O. (2016). European Lifelong Guidance Policy Network representatives' conceptions of the role of information and communication technologies related to national guidance policies. International Journal for Educational and Vocational Guidance, 16 (3), 327-342.

doi:10.1007/s10775-015-9313-7

All material supplied via JYX is protected by copyright and other intellectual property rights, and duplication or sale of all or part of any of the repository collections is not permitted, except that material may be duplicated by you for your research use or educational purposes in electronic or print form. You must obtain permission for any other use. Electronic or print copies may not be offered, whether for sale or otherwise to anyone who is not an authorised user. 


\title{
European Lifelong Guidance Policy Network representatives' conceptions of the role of information and communication technologies related to national guidance policies
}

\author{
Jaana Kettunen \\ Raimo Vuorinen \\ Outi Ruusuvirta
}

Jaana Kettunen, Raimo Vuorinen, and Outi Ruusuvirta, Finnish Institute for Educational

Researcch, University of Jyväskylä, Finland. Correspondence concerning this article should be addressed to Jaana Kettunen, at Finnish Institute for Educational Research, University of Jyväskylä, P.O.Box 35, 40014 University of Jyväskylä, Finland (e-mail:

jaana.h.kettunen@jyu.fi). 
European Lifelong Guidance Policy Network representatives' conceptions of the role of information and communication technologies related to national guidance policies Over recent decades, the role of information and communication technologies (ICT) related to lifelong guidance services has attracted increasing attention from policy-makers and other stakeholders. Lifelong guidance has been recognised as a crucial dimension of lifelong learning, promoting both social and economic goals: in particular, improving the efficiency and effectiveness of education, training, and the labour market through its contribution to reducing drop-out, preventing skill mismatches, and boosting productivity (ELGPN, 2012b). A number of European case studies and reviews strongly indicate that the demand for guidance far exceeds the supply of services, and citizens' needs cannot be met by relying exclusively on the traditional forms of guidance (e.g., ELGPN, 2010; Sultana, 2004; Sultana \& Watts, 2006; Zelloth, 2009; Watts \& Sultana, 2004). Moreover, consistency exists in various policy documents (e.g., Cedefop, 2011; Eurobarometer, 2014; European Council 2004, 2008; OECD, 2004a, 2004b) reflecting a growing consensus that the role of ICT in the guidance service sector is both important and becoming increasingly essential.

Within the European Union (EU), extending the use of ICT is one of the main initiatives put forward to strengthen lifelong guidance services. A particular focus on the theme has appeared regularly since the mid-1980s, and six European conferences on the use of ICT in guidance have been held since that time (Watts, 2010). The focus of attention in these conferences has changed due to the evolution of technology, but the core underlying issue has remained much the same. Information and communication technology is continuously viewed as a tool, as an alternative, and as an agent of change in guidance (e.g., Watts, 1986, 1996, 2010). While policy-makers have sometimes tended to view new technology in the first two of these guises (e.g., Hooley, Hutchinson \& Watts, 2010; Watts, 2002, 2010), recent research (Kettunen, Vuorinen, \& Sampson, 2013, in press) indicates that 
new technology is not only a tool or an alternative, but an interactive working space where collaboration —with and without practitioners - increasingly occurs and where new technology is being recognised for its significance. This technology is enabling countries to provide a cohesive and co-ordinated approach to delivering integrated guidance services. In addition, ICT acts as a powerful agent of change that illustrates the interconnectedness of education, employment, and social policies. It can be used in promoting accountability and transforming separate lifelong guidance services into a coherent, integrated guidance system and connecting them to wider national eGovernance structures (ELGPN, 2010).

According to Watts (1996) three factors have fuelled the growth of policy-makers' interest in the use of ICT in lifelong guidance: the potential to increase cost-effectiveness, an interest in enhancing the effectiveness of the guidance process, and the recognition that individuals increasingly expect guidance services to harness such technology. Social media in particular is becoming an increasingly important component of guidance services (e.g., Kettunen, Sampson \& Vuorinen, 2015). Some of the key issues facing policy-makers concerning the role of ICT in national and regional career information and guidance systems include funding, quality assurance, and technical upskilling of career professionals (e.g., Bimrose, Hughes, \& Barnes, 2011; Hooley et al., 2010; Watts, 2002). The European Lifelong Guidance Policy Network (ELGPN, 2010) connects ICT to the following seven policy and implementation challenges in widening access: coherence and consistency in service design, channelling, differentiation, penetration, targeting, marketing, and co-creating the services. Sampson, Dozier, and Colvin (2011) emphasise that extending access is an issue of socialjustice. The issue of whether the service structure for ICT-based services should be centralised or localised also remains an important policy question (Watts, 2010).

Every country is unique in its infrastructure and culture regarding career resources and service delivery. The ELGPN progress reports (2010, 2012, 2014) reveal that while more 
traditional services are widely used, the extent to which European countries make use of ICT in guidance varies substantially. Accordingly, policy and policy-makers have an importantin fact crucial — role in facilitating the integration of ICT into guidance services through evidence based policy-making and practice across Europe (e.g., Watts, 1996, 2009). In order to achieve this aim, more detailed research on the role of ICT related to national lifelong guidance policies is needed.

\section{Aim and research question}

The present study examines conceptions of the role of ICT in relation to national lifelong guidance policies among ELGPN national representatives. The aim of the study is to identify and describe the qualitatively different conceptions of the phenomenon. The study was guided by the following research questions: (1) What are ELGPN representatives’ conceptions of the role of ICT in relation to national lifelong guidance policies? (2) What are the critical aspects that differentiate the qualitatively varying ways of understanding the phenomenon? The ultimate aim in describing the variation in conceptions is to expand the understanding of critical aspects that may have an important role in relation to further developments and the successful implementation of existing and emerging technologies in the guidance service sector.

\section{Methods}

This study adopted a phenomenographic approach (Åkerlind, 2005b; Marton, 1986; Marton \& Booth, 1997; Marton \& Pong, 2005). Phenomenographic research reveals the qualitatively different conceptions or ways of experiencing the target phenomenon at the collective level (Marton \& Booth, 1997). The different ways of understanding the same phenomenon may phenomenographically be understood as part of a larger whole, the collective sum of ways of understanding (Åkerlind, McKenzie, \& Lupton, 2014). The research outcome contains a hierarchically structured set of categories that describe people's 
qualitatively different conceptions of the phenomenon in question (Marton, 1986). According to Marton and Booth (1997), categories of description should meet three quality criteria: each category should describe a distinctly different way of conceiving the phenomenon, a logical relationship between each category should be hierarchically represented, and there should be a limited, parsimonious number of different categories that describe the variation across the sample. The process used to ensure quality descriptions in this study is described in the data analysis section.

\section{Participants and the context of the study}

The participants in this study were designated governmental and non-governmental representatives from ELGPN member countries. The respondents represented ministries responsible for guidance policies (education, employment and social policies), public employment services, education agencies, research institutions, and national bodies of counselling professionals, thus covering the entire European guidance community. The participants responded to an emailed questionnaire sent by the ELGPN Co-ordination Unit as country teams (one response per country) during the summer of 2014. Responses were received from the following 25 country teams: Austria, Belgium, Croatia, Cyprus, Czech Republic, Denmark, Estonia, Finland, France, Germany, Greece, Hungary, Iceland, Ireland, Latvia, Lithuania, Luxembourg, Malta, Netherlands, Norway, Poland, Portugal, Sweden, Turkey and the United Kingdom. Seven country teams did not response. National teams that answered the questionnaire consisted altogether 104 delegates, of whom 71 were women, and 33 men. In terms of affiliation, 46 were government employees in ministries of education and employment; 40 were civil servants in education and labour sectors; and 22 represented national guidance forums, centres or associations. All responses have been ascribed to the country team indicated in a written response. Some answers may have been given on behalf of several persons, but this was not specified in the written responses. The data collection was 
organised as part of an ELGPN survey on the progress of national lifelong guidance strategies to feed the discussions at the 5th European Conference on Lifelong Guidance Policies held in Rome, Italy, in October 2014.

\section{Data collection}

Data for the present study were collected using open-ended questions in a survey in which participants were asked to provide written responses. Since the primary focus was on capturing the richness of the collective experience of the participants located across Europe, the open-ended survey method was deemed to be the most appropriate means of data collection. This method was considered particularly suitable because the data could be collected in a relatively short period of time. Although this approach provides little or no opportunity to interrogate the responses for further meaning, it has been successfully applied in a number of previous phenomenographic studies (e.g., Crawford, Gordon, Nicholas, \& Prosser, 1994; Tynjälä, 1997; Loughland, Reid, \& Petocz, 2002; Stokes, Magnier, \& Weaver, 2011).

The survey was sent via email to all ELGPN member country delegations in June 2014. The ELGPN country teams, each consisting of two to seven persons, were asked to provide a maximum of 1400-word country specific response to questions on key developments on the use of ICT in relation to the national lifelong guidance policies. The three open-ended questions were: (a) Describe key policy-supported national online career services that focus on the following tasks: delivering career resources, delivering distance career services, promoting accountability and means of integrating lifelong guidance services.

(b) What attention is given to ICT in national guidance strategies or other relevant policies on lifelong guidance in your country? (c) What is the extent and nature of government funding to support these developments? The length of the answers varied from half a page to three pages, the average being two pages. The overall data consisted of 48 pages (A4, single space). 
The phrasing of the survey questions was informed by the six previous European ad hoc conferences on the use of ICT in guidance and previous studies of policy issues relating to the use of ICT in lifelong guidance (e.g., Watts, 1986, 1996, 2002). Three researchers with significant experience in ICT in guidance as well as guidance policy in general reviewed and validated the survey questions.

\section{Data Analysis}

Data analysis was conducted using a phenomenographic approach ( $\AA$ kerlind, 2005b; Marton \& Booth, 1997; Marton \& Pong, 2005). Variation exists in approaches used for phenomenographic data analysis regarding whether the focus should be on the whole transcript (Bowden, 1995, 2000), large chunks of each transcript (Prosser, 2000), or on quotations that have been extracted from the data (Marton, 1986). In the present study, the approach taken was to begin an initial reading of the transcripts as a whole in order to establish interrelated themes before subsequently considering the transcript in large sections and selecting excerpts that exemplify variation and meaning. The use of the entire transcript, or of large sections of each transcript, had the purpose of increasing accuracy in the interpretation of the answers.

The first phase of the analysis focused on identifying and describing ELGPN representatives' conceptions of the role of ICT related to national lifelong guidance policies in general terms. Written responses to an open-ended survey were considered as a whole and repeatedly re-read to identify the underlying foci and intentions expressed in them. In order to identify key relationships that relate them to and distinguished them from each other, subsequent readings of the responses focused on similarities and differences in the expressed meanings. Gradually, by comparing and contrasting identified similarities and differences, a draft set of descriptive categories for collective meaning was developed, defined and named. 
The categories of description were not pre-determined, but were constituted in relation to the data.

The second phase of the analysis focused on delineating the logical relationships between the various categories. Themes that ran through and across the data were identified and used to structure the logical relationships both within and between the categories (Åkerlind, 2005a). The aim was to reveal one way of seeing a phenomenon in comparison to another, more complex one (Åkerlind, 2005a; Marton \& Booth, 1997), indicated by an increasing breadth of awareness of different aspects of the phenomenon being investigated.

To ensure a robust analysis, the data were initially analysed by the first author. Then second opinions were obtained from colleagues with whom the first author had met several times to discuss and revise the categories and their structures to confirm the validity of the data interpretations. Iterative re-reading and re-drafting were repeated until saturation occurred; that is, until the re-reading failed to produce any significant change in the categories of description (Bowden \& Green, 2010).

\section{Results}

Analysis of the data revealed four distinct categories of description that reflected ELGPN representatives' conceptions of the role of ICT in relation to national lifelong guidance policies (Table 1). The role of ICT in relation to national lifelong guidance policies was conceived as 1) unexploited, 2) emerging, 3) acknowledged but fragmented, and 4) strategic. The categories formed were nested and inclusive, expanding from the least to the most complex understanding. The aspects of phenomenon that differentiate the categories are called dimensions of variation. They comprised the critical aspects for expanding a more complete or complex level of understanding. These dimensions were named policy/strategy focus, rationale for ICT use, approach to ICT, function of ICT, distance career services, funding, and monitoring/evaluation focus. 
Table 1. ELGPN representatives' conceptions of the role of information and communication technologies in relation to national lifelong guidance policies

Each category is further detailed below. Excerpts from relevant written responses are included to illustrate key aspects of the categories. It is important to note that this categorization represents collective-rather than individual, country specific—conception of the role of ICT in relation to national lifelong guidance policies.

\section{Description of the Categories}

\section{Category 1: The role of information and communication technologies in relation} to national lifelong guidance policies is unexploited. In the first category, the role of ICT in relation to national lifelong guidance policies is conceived as unexploited. The main focus described in strategies or relevant policies in lifelong guidance is on gathering and publishing information. A key rationale for the use of ICT in career service provision relates to costs, especially to the cost-reduction potential of the tool.

"There is strong focus on gathering data/information, and publishing these data in tailor made websites ...”

"It is widely recognised that the ICT tools have great potential for making access to lifelong guidance services cheaper.”

The approach to ICT in this category is technology focused, meaning that the emphasis is placed on developing various tools, databases, information systems and ways of designing these technologies as a means for delivering information. In this category, national distance career services are currently non-existent.

\footnotetext{
"As a result of this project [to support the counsellors in the use of new technologies] nine different tools were created for the counsellors ..."
} 
"We focus on developing the National Portal for Vocational Guidance...its aim is to design the most effective webpage filled with the most up-to-date information and career resources.”

"Such practices [distance career services] do not exist at the moment nor is there a national strategy for developing such infrastructure at least for the near future.”

Respondents indicated that it is difficult to secure funding for developing the use of ICT in guidance provision. Initial efforts are increasingly dependent upon short-term funding, linked to specific projects. A challenging economic climate and previous negative experiences with system developments have affected the national funding. Attention in monitoring and evaluating of ICT-based services is primarily focusing on assessing the quantitative indicators, statistics, and volume of resource usage.

“The tight budgetary controls imposed on [country name] make it even harder to allocate funds for such activities [for the use of ICT in guidance provision].”

"The number of e-platform visits are being registered and analysed on a regular basis in order to monitor the usage.”

This category represents the least complex conception emerging from the analysis of the written responses. A defining feature of this category is that national strategies or relevant policies emphasise gathering and publishing information.

\section{Category 2: The role of information and communication technologies in relation} to national lifelong guidance policies is emerging. In the second category, the role of ICT in relation to national lifelong guidance policies is conceived as emerging. The main focus in strategies or relevant policies in lifelong guidance is now placed on developing the use of ICT. A key rationale for the use of ICT is to widen and extend access to guidance and information to an ever-increasing number of people through more developed online services.

"The public employment sector is currently placing big resources in developing and renewing interactive web-services through different channels ...” 
“The [web] service provides easy access to independent information, and guidance ...”

The approach to ICT is now content focused, meaning that the emphasis is placed on content-centred communication and ways of using ICT not just for delivering information but also as a medium for one-to-one communication. While in the previous category distance career services were currently non-existent, here the distanced career services are conducted by using asynchronous methods of communication where exchange of information takes place outside of real time through e-mail or web-form questions.

"The careers guidance team has felt for some time that it was high time to communicate with students in a manner that the students feel most comfortable with i.e. through technology.”

"Such helplines, where the clients may write questions that will be answered within a defined timeframe, or the possibility of sending e-mails.”

In this category, developing the use of ICT in guidance provision relies strongly on different types of ad hoc funding provided by the European programmes with national contribution. Attention in monitoring and evaluating of ICT-based services is now focused to a greater extent on qualitative indicators assessing the usability of the resources.

“The funding was European with national contributions.”

“The users can evaluate the portals by stating their level of satisfaction.”

This category extends the previous one, as the communicative features of ICT come to the foreground. A defining feature of this category is that the national strategies or relevant policies focus on developing the use of ICT.

Category 3: The role of information and communication technologies in relation to national lifelong guidance policies is acknowledged but fragmented. In this third category, the role of ICT in relation to national lifelong guidance policies is conceived as acknowledged but fragmented. The focus in strategies or relevant policies in lifelong 
guidance is now placed on maximising the use of ICT and providing more effective client services.

“... including the need to maximise the use of telephony and social media ...”

“To apply modern technology with better results ...”

The approach to ICT is now methodically focused, meaning that the emphasis is placed on the methods of practise and training that improve web-based assistance. While in the previous categories ICT functioned merely as an alternative channel, here it is perceived as a complementary space for career services. The distance career services are now conducted by using synchronous methods of communication where conversation takes place in real time—or almost real time-by using telephone or chat.

"The [national agency] develops a one-to-one vocational guidance chat involving a qualification of special guidance chat practitioners.”

"A helpline and web chat service, so young people and adults can discuss their options at a time and place that suits them, and make an informed choice.”

In this category, different public actors at ministerial or regional level co-fund the national online services. Attention in monitoring and evaluating services is now directed at generating the data indicators required to assess the impact of and client satisfaction with services.

“The Federal Ministry of Education and Research funds the developmental work for guidance activities including the national telephone hotline and internet portal for educational guidance. Provisions under the responsibility of the federal states are usually funded by the educational ministries of these states.”

“The Careers Service uses client satisfaction questionnaires to gather feedback.” 
The conception represented by this category is more complex than that of previous categories, as it includes awareness of an increasing number of aspects of the role of ICT in relation to national lifelong guidance policies. A defining feature of this category is that national strategies or relevant policies focus on maximising the use of ICT.

\section{Category 4: The role of information and communication technologies in relation} to national lifelong guidance policies is strategic. In this fourth category, the role of ICT in relation to national lifelong guidance policies is strategic. The focus in strategies or relevant policies in lifelong guidance is on systematising the use of ICT and improving the quality and efficiency of career guidance services through more efficient use of ICT resources and skills.

“[National unit for lifelong guidance] is leading a working group with national stakeholders. This group considers the possibilities for development of national cross sectoral online services in career guidance.”

"The objective is to apply modern technology in a more efficient way ..."

The approach to ICT in this category is systemically focused. This means the emphasis is placed on rethinking the organisational culture of career services and developing a more integrative role of ICT in creating a common conceptual framework for modelling the services. Attention is also given to the role of ICT in national legislation. Unlike in the previous categories, ICT now functions as an impetus for change and reform in career services. Moreover, national distance career services are now conducted using multisynchronous ways of communication where direct communication and asynchronous means are combined to satisfy the varying needs of individuals. These public services are available beyond the traditional career services office hours of career services.

"A new law on guidance is launched and attention to eGuidance is strengthened." 
"Every person who seeks information on education and employment can receive guidance from experienced counsellors via various communication channels (chat, telephone, e-mail, SMS and Facebook) every day of the week [...] which means that clients can get in touch with a guidance counsellor on a Tuesday evening or Saturday afternoon.”

In this category, funding for national online services is provided and coordinated by the state. Attention in monitoring and evaluating is now moving to data indicators that require the generation of measures to ensure performance accountability. The aim is to assist decision- makers by providing more objective data on performance, effectiveness, and efficiency.

"Both the national Internet-based guidance portal and eGuidance service are based on government funding."

"This 'data warehouse' is not only an ICT statistic and evaluation tool, but also an instrument for controlling and policy decision making in labour market policy and career guidance.”

This category represents the most complex conception emerging from the analysis of the written responses, as it is inclusive of the conceptions represented by the preceding categories. A defining feature of this category is that the focus in national strategies or relevant policies is placed on systematising the use of ICT.

\section{Relationship Between the Categories}

The categories of description were delimited from each other and organized hierarchically through dimensions of variation that emerged from the data. Due to the hierarchical nature of categories, some conceptions can be regarded as more complete and more complex than others (Åkerlind, 2005a).

The focus in strategies or relevant policies changed across the categories of description. The distinct difference in category 1 , in relation to other categories, was that the focus in strategies or relevant policies was mainly on gathering and publishing information, whereas in more complex categories, the focus was also on developing the use of ICT. 
Maximising the use of ICT was defined as a main focus area in category 3, where the role of ICT in relation to national lifelong guidance policies is acknowledged but fragmented. In the most complex category, the focus in strategies or relevant policies was placed on systematising the use of ICT.

Shifts in the rationale for using ICT appeared as transitions from potential low-cost means of increasing access to guidance and information to improving the quality and efficiency of career services. In the least complex categories, the key rationale for ICT use was the potential of reducing the costs (category 1) and widening access to guidance and information (category 2). A turning point occurred in category 3, where the role of ICT in relation to national lifelong guidance policies is acknowledged but fragmented, as this marked a change in the underlying rationale for using ICT from enhancing access to providing more effective client services. In the most complex category, the potential to improve the efficiency of career services provided the key rationale for ICT use.

The approach to ICT changed across the categories of description. The most distinctive difference in category 1 , in relation to the other categories is the technology focused approach to ICT. A shift from technology to a content-focused approach was discerned in category 2, where the role of ICT related to national lifelong guidance policies is emerging. A turning point was seen again in category 3, where ICT's role related to national lifelong guidance policies is acknowledged but fragmented, as this category marked a change in approach from being mainly technology and content focused to being pedagogically focused. In the most complex category, where the role of ICT in relation to national lifelong guidance policies is strategic, a shift to a systemically focused approach was discerned.

In terms of the function of ICT, the transition across the categories was from the means for delivering information to an impetus for change and reform. In category 1 , where the role of ICT in relation to national lifelong guidance policies is unexploited, the distinct 
difference in relation to other categories was that ICT functioned merely as a means for delivering information. A change from emphasising the information transmission function to viewing ICT as a medium for one-to-one communication was discerned in category 2, where the role of ICT in relation to national lifelong guidance policies is emerging. A turning point occurred in category 3, as it marked a change in the function of ICT from being an alternative information and communication channel to being a space for career services. A significant shift where ICT began to function as an impetus for change and reform was discerned in category 4, where the role of ICT in relation to national lifelong guidance policies is strategic.

Distance career services were characterised differently in all categories. In category 1 , where the role of ICT in relation to national lifelong guidance policies is unexploited, the distinct difference in relation to other categories was that distance career services were nonexistent. A shift from non-existent to distance asynchronous career services was discerned in category 2, where the role of ICT in relation to national lifelong guidance policies is emerging. In the most complex categories, the distance career services extended to include synchronous (real time or near real time) interactions (category 3) and multi-synchronous (category 4) interactions where direct communication and asynchronous means were combined.

In terms of funding, the transition across the categories was from project to state coordinated funding. In the least complex categories, the identifiable funding for developing the use of ICT in guidance provision relied on different types of project (category 1) and programme (category 2) funding. Co-funding among different public actors at the ministerial or regional levels was discerned in category 3, where the role of ICT in relation to national lifelong guidance policies is acknowledged but fragmented. In the most complex category, where the role of ICT in relation to national lifelong guidance policies is strategic a shift to state provided and coordinated funding was identified. 
Monitoring and evaluation focus expanded across the categories. In category 1 , quantitative indicators, statistics and volume of resource usage was the main focus of monitoring and evaluation, whereas in category 2 , greater attention was given to qualitative indicators focusing on the usability of the resources. In category 3 , where the role of ICT in relation to national lifelong guidance policies is acknowledged but fragmented, monitoring and evaluating extended to impact and client satisfaction with the services. In the most complex category, the emphasis was placed on monitoring and evaluating accountability.

\section{Discussion}

This study identified ELGPN representatives' conceptions of the role of ICT in relation to national lifelong guidance policies in four distinct categories of description ranging from unexploited to strategic. Seven dimensions of variation were identified: policy/strategy focus, rationale for ICT use, approach to ICT, function of ICT, nature of online services, distance career services, and funding and monitoring/evaluation focus.

The findings show similarities with previous studies but also provide new insight into developments of the role of ICT in national lifelong guidance policies. The main similarities with earlier studies and policy documents (e.g., Cedefop, 2011; ELGPN, 2010, 2012; OECD, 2004a) can be found in the first three categories, where the role of ICT in relation to national lifelong guidance policies is unexploited, emerging and acknowledged but fragmented. Similarities exist in this study between observations on the key issues facing policy makers concerning the use of ICT in guidance and those described by Bimrose et al. (2011), which include funding, quality assurance, and technical upskilling of career professionals. Some countries report difficulties in securing funding to develop the use of ICT in lifelong guidance. On the other hand, some countries have been able to effectively use either cofunding mechanisms or governmental funding for national online services.

The findings also further support the recent observations on the approach to existing 
and emerging technologies in guidance (Kettunen et al., 2015), and Watts'(1986, 1996, 2010) earlier observation that ICT is continuously viewed as a tool, as an alternative, or as an agent of change. The most complex category in this study supports ELGPN’s (2010) notion that ICT can be the means for transforming sector-based and provider-centred provision into a user-centred and coherent lifelong guidance system. In this category, the focus in strategies and relevant policies was placed on systemising the use of ICT; more efficient use of ICT resources and skills was emphasised, a multi-synchronous distanced services delivery mode was embraced, state provided and coordinated funding was discerned, and the emphasis was placed on measures that ensure performance accountability.

The findings show that understood function of ICT, and focus on strategies and policies appear to be interrelated. Based on of our findings, we would argue that policymakers and other stakeholders should recognise the variation that exists in the current understanding of ICT's role in relation to national lifelong guidance policies. Moreover, they should understand the critical differences between their current understanding and the more advanced understanding they could potentially move towards. This understanding is important when considering the development and successful implementation of existing and emerging technologies in the guidance service sector. If the understood function of the ICT remains solely as an information delivery channel, the full potential is not utilized neither in formation of lifelong guidance policies nor in the integrated service delivery. The implementation of a strategic approach in the use of ICT in relation to lifelong guidance requires a jointly agreed cross-ministerial strategy for lifelong guidance and a common conceptual framework for the service delivery and funding. To avoid fragmentation and to maintain and strengthen the political momentum of lifelong guidance policy development, it is necessary to further enhance the synergies among different guidance actors and stakeholders at national, regional, and local levels and to include the use of ICT in the 
guidance service sector in national eGovernance strategies.

\section{Conclusion}

By exploring the logical relationships between qualitatively different conceptions, this study provides policy-makers and other stakeholders a way to holistically view the varying role of ICT in relation to national lifelong guidance policies across the EU. The hierarchical structure of the categories enables policy-makers and other stakeholders to deepen their understanding of the development and successful implementation of existing and emerging technologies in the guidance service sector using the identified critical aspects. The matrix presented in this article may serve as a catalyst for discussing and formulating a common conceptual framework for integrated all-age guidance services. The categorisation can be used to map the approach in the lifelong guidance policy development at the national and international levels. In addition, the hierarchical structure of the findings may serve as a tool for evaluating further developments regarding the role of ICT in the national lifelong guidance policy development at the national as well as international levels. 
References

Åkerlind, G. (2005a). Learning about phenomenography: Interviewing, data analysis and qualitative research paradigm. In J. A. Bowden \& P. Green (Eds.), Doing developmental phenomenography (pp. 63-73). Melbourne: RMIT University Press.

Åkerlind, G. S. (2005b). Variation and commonality in phenomenographic research methods. Higher Education Research \& Development, 24, 321-334.

doi:10.1080/07294360500284672

Åkerlind, G., McKenzie, J., \& Lupton, M. (2014). The potential of combining phenomenography, variation theory and threshold concepts to inform curriculum design in higher education. In J. Huisman \& M. Tight (Eds.), Theory and Method in Higher Education Research II (pp. 227-247). Emerald Group Publishing Limited.

Bimrose, J., Hughes, D., \& Barnes, S.-A. (2011). Integrating new technologies into careers practice: Extending the knowledge base. London: UK Commission for Employment and Skills.

Bowden, J. (1995). Phenomenographic research: Some methodological issues. Nordisk Pedagogik, 15, 144-155.

Bowden, J. (2000). The nature of phenomenographic research. In J. Bowden \& E. Walsh (Eds.), Phenomenography (pp. 1-18). Melbourne, Australia: Royal Melbourne Institute of Technology.

Bowden, J. A., \& Green, P. J. (2010). Relationality and the myth of objectivity in research involving human participants. In J. Higgs, N. Cherry, R. Macklin \& R. Ajjawi (Eds.), Researching practice - A discourse on qualitative methodologies (pp. 105-121). Rotterdam: Sense Publishers.

Cedefop (2011). Lifelong guidance across Europe: reviewing policy progress and future prospects. Luxembourg: Publications Office of the European Union. 
Collier-Reed, B., \& Ingerman, Å. (2013). Phenomenography: From Critical Aspects to Knowledge Claim. In J. Huisman, and M. Tight (Eds.), Theory and Method in Higher Education Research (International Perspectives on Higher Education Research, Volume 9) (pp. 243-260). Emerald Group Publishing Limited.

Crawford, K., Gordon, S., Nicholas, J., \& Prosser, M. (1994). Conceptions of mathematics and how it is learned: The perspectives of students entering university. Learning and Instruction, 4, 331-345.

ELGPN [European Lifelong Guidance Policy Network]. (2010). Lifelong Guidance Policies: Work in Progress. A report on the work of the European Lifelong Guidance Policy Network 2008-2010. Jyväskylä, Finland: University of Jyväskylä.

ELGPN [European Lifelong Guidance Policy Network]. (2012). A European Lifelong Guidance Policies: Progress Report 2011-12. A report on the work of the European Lifelong Guidance Policy Network 2011-12. Saarijärvi, Finland.

ELGPN [European Lifelong Guidance Policy Network]. (2012b). Lifelong guidance policy development: A European resource kit. Saarijärvi, Finland.

ELGPN [European Lifelong Guidance Policy Network]. (2014). A European Lifelong Guidance Policies: Progress Report 2013-14. A report on the work of the European Lifelong Guidance Policy Network 2013-14. Saarijärvi, Finland.

Eurobarometer (2014). Special Eurobarometer 417. European Area of Skills and Qualifications. European Commission, Brussels.

European Council 2004. Draft Resolution of the Council and of the representatives of the Member States meeting within the Council on Strengthening Policies, Systems and Practices in the field of Guidance throughout life in Europe. Council of the European Union, 18 May 2004. Brussels, EU. 
European Council (2008). Draft Resolution of the Council and of the Representatives of the Government of the Member States, meeting within the Council, on better integrating lifelong guidance into lifelong learning strategies. Brussels, EU.

Hooley, T., Hutchinson, J., \& Watts, A. G. (2010). Careering through the web. The potential of web 2.0 and 3.0 technologies for career development and career support services. London: UK Commission for Employment and Skills.

Kettunen, J., Sampson, J.P., \& Vuorinen, R. (2015). Career practitioners' conceptions of competency for social media in career services. British Journal of Guidance \& Counselling. doi:10.1080/03069885.2014.939945

Kettunen, J., Vuorinen, R., \& Sampson, J. P. (2013). Career practitioners’ conceptions of social media in career services. British Journal of Guidance \& Counselling, 41, 302317. doi:10.1080/03069885.2013.781572

Kettunen, J., Vuorinen, R., \& Sampson, J. P. (in press). Practitioners’ Experiences of Social Media in Career Services. The Career Development Quarterly.

Loughland, T., Reid, A., \& Petocz, P. (2002). Young People's Conceptions of Environment: A phenomenographic analysis. Environmental Education Research, 8, 187-197. doi:10.1080/13504620220128248

Marton, F. (1986). Phenomenography - A research approach investigating different understandings of reality. Journal of Thought, 21, 28-49.

Marton, F. \& Booth, S. (1997). Learning and awareness. Mahwah, NJ: Lawrence Erlbaum Associates, Publishers.

Marton, F. \& Pong, Y. W. (2005). On the unit of description in phenomenography. Higher Education Research \& Development, 24, 335-348. doi:10.1080/07294360500284706

OECD [Organisation for Economic Co-operation and Development]. (2004a). Career Guidance and Public Policy: Bridging the Gap. Paris, France: OECD. 
OECD [Organisation for Economic Co-operation and Development]. (2004b). Career Guidance: A handbook for policy makers. Paris, France: OECD.

Prosser, M. (2000). Using phenomenographic research methodology in the context of research in teaching and learning. In J. Bowden \& E. Walsh (Eds.), Phenomenography (pp. 34-46). Melbourne, Australia: Royal Melbourne Institute of Technology.

Sampson, J.P., Dozier, V.C., \& Colvin, G.P. (2011). Translating career theory to practice: the risk of unintentional social injustice. Journal of Counselling and Development, 89, 326-337. doi:10.1002/j.1556-6678.2011.tb00097.x

Stokes, A, Magnier, K., \& Weaver, R. (2011). What is the use of fieldwork? Conceptions of students and staff in geography and geology. Journal of Geography in Higher Education, 35, 121-141. doi:10.1080.03098265.2010.487203.

Sultana, R.G. (2004). Guidance Policies in the Knowledge Society: Trends, challenges and responses across Europe: A Cedefop synthesis report. Cedefop Panorama Series 85. Luxembourg: Office for Official Publications of the European Communities.

Sultana, R. G., \& Watts, A. G. (2006). Career guidance in Public Employment Services across Europe. International Journal for Educational and Vocational Guidance, 6, 29-46. doi:10.1007/s10775-006-0001-5

Tynjälä, P. (1997). Developing education student' conceptions of the learning process in different learning environments. Learning \& Instruction, 7, 277-292. doi: 0.1016/S0959-4752(96)00029-1

Zelloth, H. (2009). In demand: Career guidance in EU neighbouring countries. Luxembourg: Office for Official Publications of the European Communities.

Watts, A.G. (1986). The role of the computer in careers guidance. International Journal for the Advancement of Counselling, 9, 145-158. doi:10.1007/BF00129409. 
Watts, A. G. (1996). Computers in guidance. In Rethinking careers education and guidance: Theory, policy and practice, Edited by: Watts, A. G., Law, B., Killeen, J., Kidd, J. M. and Hawthorn, R. 269-286. London: Routledge.

Watts, A. G. (2002). The role of information and communication technologies in integrated career information and guidance systems: A policy perspective. International Journal for Educational and Vocational Guidance, 2, 139-155.

doi:10.1023/A:1020669832743

Watts, A. G. (2009). Career guidance and public policy. In J.A. Athanasou \& R. Van Esbroeck (Eds.), International handbook of career guidance, (pp. 341-353). Berlin: Springer.

Watts, A.G. (2010). Policy issues relating to the use of ICT in lifelong guidance. Career Research Development: The NICEC Journal, 25, 33-39.

Watts, A.G. \& Sultana, R. G. (2004). Career guidance policies in 37 countries: contrast and common themes. International Journal for Educational and Vocational Guidance, 4, 105-122. doi:10.1007/s10775-005-1025-y 


\section{CATEGORIES}

\begin{tabular}{lllll}
$\begin{array}{l}\text { DIMENSIONS OF } \\
\text { VARIATION }\end{array}$ & unexploited & \multicolumn{1}{c}{ emerging } & \multicolumn{1}{c}{$\begin{array}{c}\text { acknowledged } \\
\text { but fragmented }\end{array}$} & strategic \\
\hline $\begin{array}{l}\text { Policy/strategy } \\
\text { focus }\end{array}$ & $\begin{array}{l}\text { gathering and } \\
\text { publishing } \\
\text { information }\end{array}$ & $\begin{array}{l}\text { developing the } \\
\text { use of ICT }\end{array}$ & $\begin{array}{l}\text { maximising the } \\
\text { use of ICT }\end{array}$ & $\begin{array}{l}\text { systematising } \\
\text { the use of ICT }\end{array}$ \\
\hline $\begin{array}{l}\text { Rationale for } \\
\text { ICT use }\end{array}$ & costs & $\begin{array}{l}\text { widening } \\
\text { access }\end{array}$ & effectiveness & efficiency \\
\hline $\begin{array}{l}\text { Approach } \\
\text { to ICT }\end{array}$ & technology & $\begin{array}{l}\text { content } \\
\text { focused }\end{array}$ & $\begin{array}{l}\text { methodologically } \\
\text { focused }\end{array}$ & $\begin{array}{l}\text { systemically } \\
\text { focused }\end{array}$ \\
\hline $\begin{array}{l}\text { Function } \\
\text { of ICT }\end{array}$ & $\begin{array}{l}\text { means for } \\
\text { delivering }\end{array}$ & $\begin{array}{l}\text { medium for } \\
\text { one-to-one }\end{array}$ & $\begin{array}{l}\text { space for } \\
\text { career services }\end{array}$ & $\begin{array}{l}\text { impetus for } \\
\text { change and } \\
\text { reform }\end{array}$ \\
\hline $\begin{array}{l}\text { Distance career } \\
\text { services }\end{array}$ & non-existent & asynchronous & synchronous & $\begin{array}{l}\text { multi- } \\
\text { synchronous }\end{array}$ \\
\hline $\begin{array}{l}\text { Funding } \\
\text { information }\end{array}$ & project & programme & co-funding & $\begin{array}{l}\text { state } \\
\text { coordinated }\end{array}$ \\
\hline $\begin{array}{l}\text { Monitoring/ } \\
\text { evaluation focus }\end{array}$ & volume & usability & impact & accountability \\
\hline
\end{tabular}

